\title{
Karakterisasi Reservoar Hidrokarbon Mengunakan Metode Seismik Inversi Deterministik Model Based Pada Lapangan Penobscot Kanada
}

\author{
Aulia Latifah*, Dwi Pujiastuti, Elistia Liza Namigo \\ Laboratorium Fisika Bumi, Jurusan Fisika \\ Fakultas Matematika dan Ilmu Pengetahuan Alam Universitas Andalas \\ Kampus Unand Limau Manis, Padang, 25163 Indonesia \\ *aulialatifah06@gmail.com
}

\begin{abstract}
ABSTRAK
Telah dilakukan karakterisasi reservoar hidrokarbon pada Lapangan Penobscot Kanada mengunakan metode seismik inversi deterministik model based. Penelitian ini mengunakan data seismik PSTM (post stack time migration) 3D pada inline 1300 sebagai data input dan data sumur L30 dan B41 sebagai data kontrol. Karakterisasi reservoar dilakukan dengan melakukan analisis crossplot dan menentukan nilai impedansi akustik atau acoustic impedance (AI). Analisis crossplot menunjukkan bahwa log gamma ray sensitif dalam pemisahan lapisan shale, sandstone, dan limestone. Penentuan zone of interest yang diindikasikan sebagai reservoar hidrokarbon dilakukan melalui analisis atribut dekomposisi spektral dengan frekuensi $10 \mathrm{~Hz}$. Hal tersebut menunjukkan dengan jelas kemenerusan pola penyebaran litologi yang diduga sebagai hidrokarbon dengan lebih mudah. Hasil inversi deterministik model based menunjukkan bahwa pada inline 1300 terdapat potensi hidrokarbon melalui sebaran nilai impedansi akustik. Slicing yang dilakukan pada lapisan zone of interest menunjukkan hasil sebaran nilai impedansi akustik dengan rentang 13556-27501 $(\mathrm{m} / \mathrm{s}) *(\mathrm{~g} / \mathrm{cc})$. Potensi reservoar hidrokarbon sandstone ditunjukkan melalui zona impedansi akustik pada nilai $20000-25461(\mathrm{~m} / \mathrm{s}) *(\mathrm{~g} / \mathrm{cc})$.

Kata kunci: atribut dekomposisi spektral, impedansi akustik, inversi deterministik, model based, zone of interest
\end{abstract}

\section{ABSTRACT}

The characterization of hydrocarbon reservoirs in the Penobscot Field Canada using seismic inversion deterministic model based method has been carried out. This study uses the post stack time migration (PSTM) 3D seismic data along inline 1300 as input data and well data L3O and B41 as control data. Reservoir characterization is carried out by crossplot analysis and determine the value of acoustic impedance (AI). Crossplot analysis shows that between gamma ray logs and sensitive density logs in the litology of shale, sandstone, and limestone. Determination of the zone of interest indicated as a hydrocarbon reservoir is carried out through spectral decomposition analysis with a frequency of $10 \mathrm{~Hz}$. This shows clearly the continuity of the lithological distribution pattern which is assumed to be hydrocarbons more easily. The result of deterministic model-based inversion show that on inline 1300 there is hydrocarbon potential through the distribution of acoustic impedance values. Slicing carried out at the zone of interest shows the distribution of acoustic impedance values with a range of 13556-27501 $(\mathrm{m} / \mathrm{s}) *(\mathrm{~g} / \mathrm{cc})$. The potential of a sandstone hydrocarbon reservoir is shown through the acoustic impedance zone at a value of 20000-25461 ( $\mathrm{m} / \mathrm{s}) *(\mathrm{~g} / \mathrm{cc})$.

Keywords: acoustic impedance, deterministic inversion, model based, spectral decompotition, zone of interest

\section{PENDAHULUAN}

Sumber utama yang digunakan manusia untuk memenuhi kebutuhan energi adalah minyak dan gas bumi (migas). Menurut International Energy Agency (2017), kebutuhan terhadap migas terus meningkat dengan penggunaan mencapai $81 \%$ dari porsi kebutuhan energi dunia. Namun peningkatan kebutuhan terhadap migas tidak sebanding dengan produksinya yang terus mengalami penurunan. Dalam upaya mencukupi kebutuhan terhadap energi migas maka perlu dilakukan optimasi penemuan sumber cadangan migas yang baru.

Minyak dan gas merupakan hasil dari senyawa organik yang telah bermigrasi dari batuan sumber ke batuan reservoar tempat terakumulasinya migas di dalam lapisan bumi. Dalam upaya menemukan dan mengembangkan sumber cadangan migas yang baru maka perlu dilakukan karakterisasi batuan reservoar. Syarat sebuah reservoar memiliki potensi migas dapat dilihat dari parameter karakteristik fisisnya seperti densitas, porositas, dan permeabilitas (Koesomadinata, 1980). Parameter tersebut dapat dianalisis mengunakan nilai impedansi 
akustik. Metode yang bisa digunakan untuk melakukan karakteristik terhadap reservoar adalah dengan mengunakan metode geofisika.

Metode geofisika yang banyak digunakan yaitu metode seismik refleksi untuk melihat gambaran bawah permukaan bumi yang memiliki potensi minyak dan gas. Metode tersebut memiliki kelebihan yaitu mencangkup survei dengan wilayah yang cukup luas dan hasilnya cukup baik (Badley, 1985). Salah satu metode seismik yang digunakan yaitu metode seismik inversi. Seismik inversi merupakan teknik untuk membuat model bawah permukaan bumi menggunakan data seismik sebagai input dan data sumur sebagai kontrol serta dapat menghasilkan nilai impedansi akustik sebagai parameter interpretasi (Sukmono, 2000).

Pada metode seismik inversi, parameter fisis batuan akan dihubungkan dengan nilai impedansi akustik yang dihasilkan dari proses inversi. Impedansi akustik merupakan perkalian densitas batuan dan kecepatan gelombang $\mathrm{P}$ yang mengindikasikan kemampuan batuan untuk melewatkan gelombang seismik (Sukmono, 2000). Nilai AI digunakan sebagai indikator karakteristik reservoar. Beberapa metode seismik inversi umum digunakan pada karakterisasi reservoar yaitu seismic coloured inversion (SCI), inversi stokastik, dan inversi deterministik.

Pengunaan metode inversi deterministik untuk karakterisasi reservoar hidrokarbon akan menghasilkan nilai secara kuantitatif dari karakterisasi dan penampang impedansi akustik serta membutuhkan waktu yang lebih cepat dan dapat mengunakan sedikit data sumur. Hal tersebut akan mempermudah dalam penentuan zona yang memiliki potensi reservoar pada daerah yang memiliki keterbatasan jumlah sumur. Metode inversi lainnya yaitu metode SCI tidak cocok digunakan untuk estimasi secara kuantitatif dari reservoar walaupun pengunaanya membutuhkan waktu yang cepat (Whitcombe dan Fletcher, 2001). Metode inversi stokastik membutuhkan data sumur yang lebih dari 3 dan waktu pengerjaan yang lebih lama (Cooke dan Cant, 2010).

Khasanah (2016) telah melakukan penelitian mengunakan seismik inversi deterministik model based untuk estimasi karakteristik sandstone dan didapatkan hasil sebaran hidrokarbon yang cukup baik. Namun proses inversinya tidak mengunakan atribut seismik sehingga zone of interest pada data seismik tidak dapat dilihat dengan jelas sebelum dilakukan inversi. Menurut Tullailah (2015) data seismik memiliki kelemahan dalam memberikan kenampakan adanya patahan dan bentuk badan reservoar, oleh karena itu perlu dilakukan analisis atribut seismik yang dapat memperlihatkan adanya patahan dan badan reservoar secara lebih jelas. Pengunaan metode inversi deterministik model based dan didukung oleh penambahan atribut telah dilakukan oleh Nofriyanti dan Namigo (2016) untuk melakukan karakterisasi hidrokarbon sandstone pada Lapangan F3 Laut Utara Belanda yang memiliki 2 data sumur sebagai control dan data seismik offshore sebagai input, dengan memanfaatkan metode seismik atribut yaitu dekomposisi spektral untuk menentukan zone of interest.

Penelitian ini juga akan mengunakan metode yang sama dengan Nofriyanti dan Namigo (2016), namun pada daerah penelitian yang berbeda. Daerah penelitian yang dipilih adalah Lapangan Offshore Penobscot Kanada di Cekungan Nova Scotia. Hasil akhir dari penelitian ini akan dapat memberikan gambaran sebaran nilai impedansi akustik sebagai karakterisasi reservoar untuk optimasi pengembangan potensi sumur eksplorasi baru.

\section{METODE}

\subsection{Data}

Data yang digunakan pada penelitian ini yaitu data seismik 3D PSTM (post stack time migration) dengan inline 1000-1600 dan crossline 1000-1481, data sumur yaitu sumur L30 dan B41, dan data marker. Fokus lokasi penelitian berada pada Lapangan Penobscot Kanada yang berada pada Cekungan Nova Scotia Kanada yang dapat diakses secara bebas pada http://opendtect.org/index.php/support/free-seismic-surveys.

\subsection{Pengolahan Data}

Penelitian ini mengunakan software OpendTect sebagai perangkat interpertasi dan pengolahan data. Langkah-langkah yang dilakukan pada pengolahan data dengan menggunakan metode seismik inversi deterministik model based adalah sebagai berikut : 


\subsubsection{Tahap Persiapan}

Tahap persiapan merupakan tahap download data, ekstrak data survei, input data yang dibutuhkan, dan melakukan pengaturan parameter terhadap data penelitian yang digunakan, seperti pemilihan inline dan crossline.

\subsubsection{Well Seismic Tie}

Well seismic tie (WST) merupakan pengikatan antara data log sumur dan data seismik, sehingga data seismik dalam domain waktu dapat berkorelasi dengan data log sumur dalam domain kedalaman. WST digunakan untuk mengkolerasikan informasi geologi yang diperoleh dari data sumur dan data seismik. Pada tahap ini ada beberapa proses yang dilakukan yaitu ekstraksi wavelet dan pembuatan seismogram sintetik. Ekstraksi wavelet dapat dilakukan dengan beberapa cara antara lain use well, statical, ricker, dan bandpass. Pada penelitian ini akan mengunakan cara use well yaitu ektraksi wavelet di sekitar sumur. Setelah dipilih wavelet hasil ekstraksi selanjutnya dilakukan proses pembuatan seismogram sintetik yang merupakan rekaman seismik yang dibuat dari data log sonic (DT) dan densitas. Log sonic membentuk koefisien refleksi yang selanjutnya dikonvolusikan dengan wavelet. Seismogram sintetik ini dapat membantu mengidentifikasikan horizon pada penampang seismik. Seismogram sintetik menunjukkan data kedalaman yang akurat. Proses well seismic tei dilakukan hingga mendpaatkan koefisien korelasi yang baik yaitu mendekati 1. Jika korelasi belum mendekati 1 maka dapat dilakukan proses pengeseran untuk menempatkan event reflector seismik pada kedalaman yang sebenarnya.

\subsubsection{Picking Horizon}

Tahap ini merupakan proses membuat garis horizon pada suatu kemenerusan lapisan pada penampang seismik. Pemilihan horizon ini dilakukan karena daerah tersebut dianggap sebagai zona target yang memiliki ketidakmenerusan atau disebut zone of interest.

\subsubsection{Analisis Crossplot}

Tahap analisis crossplot merupakan proses analisis zona target untuk mengetahui parameter fisis yang paling sensitif. Analisis crossplot dilakukan untuk mengetahui sensitivitas data terhadap kemampuannya untuk memisahkan litologi batuan antara shale, sandstone, dan limestone. Analisis crossplot yang dilakukan pada penelitian ini yaitu gamma ray dan impedansi akustik. Hasil dari proses ini akan dijadikan bahan interpretasi.

\subsubsection{Atribut Dekomposisi Spektral}

Tahap ini dilakukan untuk mengetahui zone of interest pada zona target. Jenis dekomposisi spektral yang digunakan adalah fourier filter transform (FFT) dengan frekuensi 5 $\mathrm{Hz}$ dan $10 \mathrm{~Hz}$ karena frekuensi tersebut dapat dengan jelas melihat kemenerusan lapisan.

\subsubsection{Seismik Inversi Deterministik}

Pada tahap seismik inversi dilakukan beberapa proses yaitu 3D Broadbrand AI Model untuk pembuatan model awal mengunakan data sumur, batas geologi horizon, parameter filter, dan volume seismik dan $2 D$ Error Grid untuk siap menyimpan model.

\subsubsection{Slicing}

Tahap ini dilakukan untuk memprediksi parameter-parameter fisis batuan dan mengetahui zone of interest yang mengandung akumulasi hidrokarbon.

\section{HASIL DAN DISKUSI}

\subsection{Analisis Well Seismic Tie}

Gambar 1 menunjukkan hasil WST dari sumur L30 dan koefisien korelasi sumur L30. Hal tersebut menunjukkan bahwa sumur L30 memiliki rentang nilai impedansi akustik sebesar $17500-27614(\mathrm{~m} / \mathrm{s})^{*}(\mathrm{~g} / \mathrm{cc})$ dan nilai densitas batuan dengan rentang 2,06-2,76 (g/cc). 


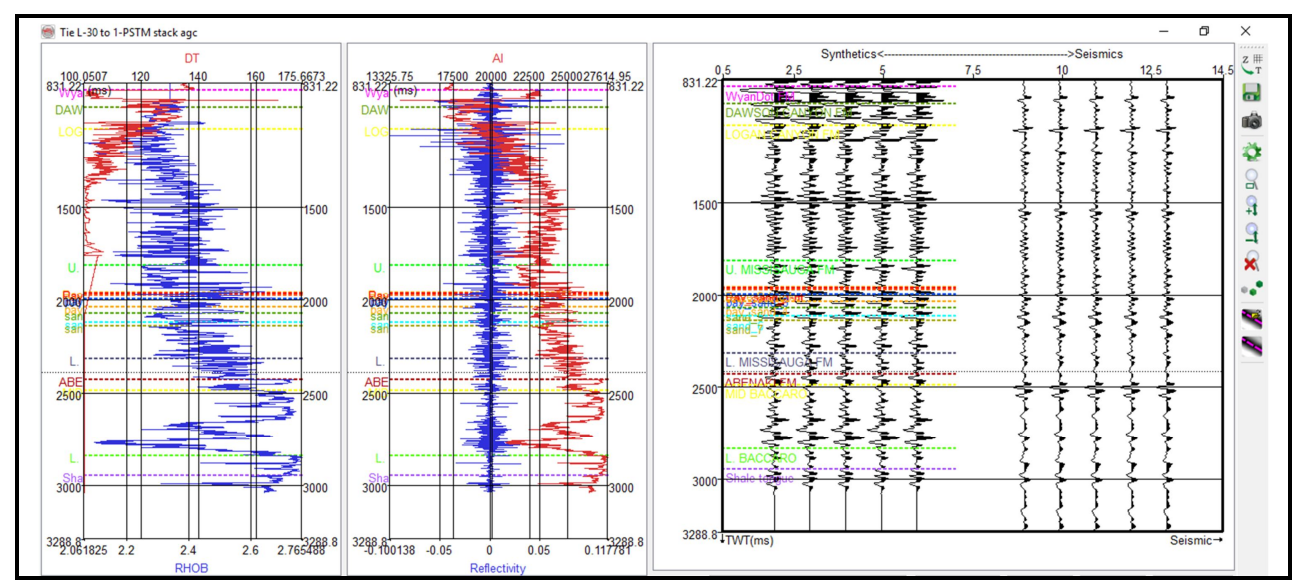

Gambar 1 Hasil Well Seismic Tie Pada Sumur L-30

Hasil WST pada sumur B41 ditunjukkan pada Gambar 2. Proses ini menghasilkan penampang seismogram sintetik dan menunjukkan bahwa di sekitar sumur B41 memiliki rentang nilai impedansi akustik sebesar 16288,40-26372,46 (m/s)*(g/cc) dan nilai densitas batuan dengan rentang 2,012-2,6 (g/cc).

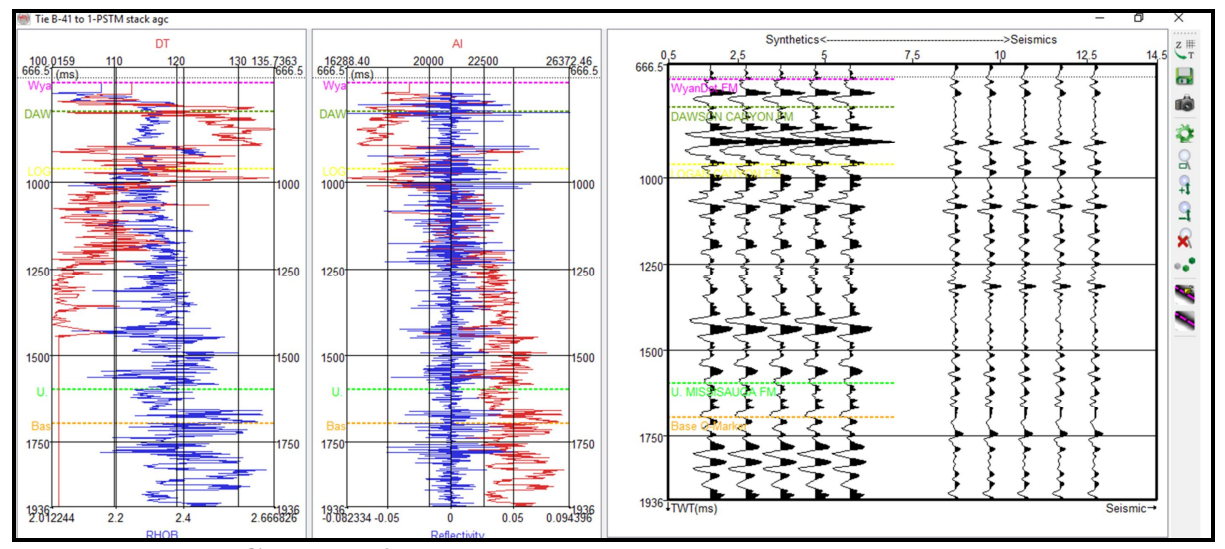

Gambar 2 Hasil Well Seismic Tie Pada Sumur B41

Gambar 3(a) menunjukkan koefisien korelasi yang didapatkan pada sumur L30 dan didapatkan hasil yang cukup baik yaitu 0,6804. Hasil pengikatan ini dapat digunakan pada proses inversi. Koefisien korelasi yang didapatkan pada proses WST di sumur B41 didapatkan hasil koefisien korelasi yaitu sebesar 0,7467 seperti pada Gambar 3(b). Hasil ini menunjukkan hasil pengikatan yang lebih baik jika dibandingkan pengikatan sumur L30.

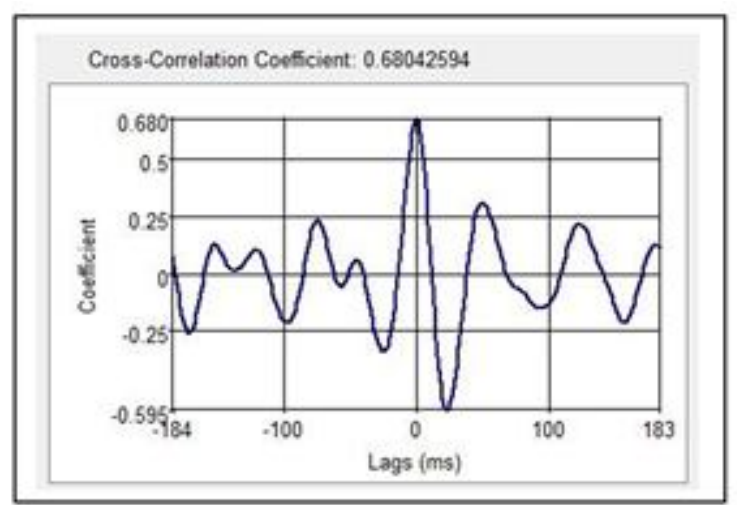

(a)

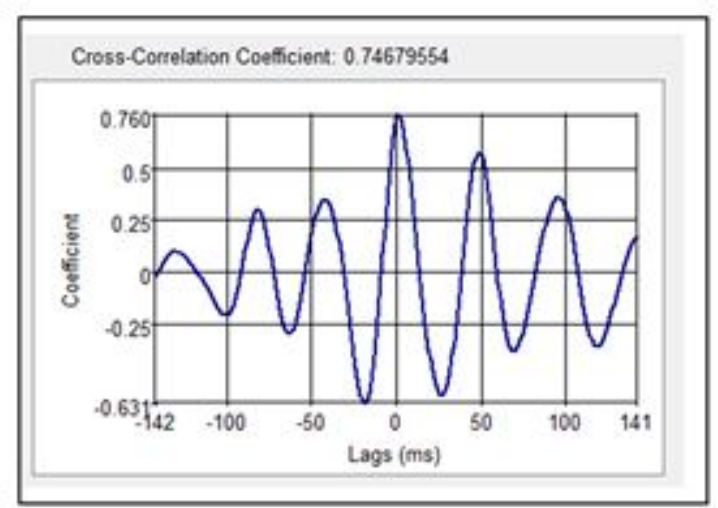

(b)

Gambar 3 Koefisien Korelasi (a) pada sumur L30 dan (b) sumur B41 


\subsection{Analisis Crossplot}

Gambar 4 menunjukkan hasil crossplot sumur L30 antara log gamma ray pada sumbu y dan impedansi akustik pada sumbu x. Dari hasil crossplot menunjukkan bahwa log gamma ray sensitif dalam pemisahan shale yang ditunjukkan pada kotak warna hijau, sandstone pada kotak warna biru, dan limestone pada kotak warna kuning.

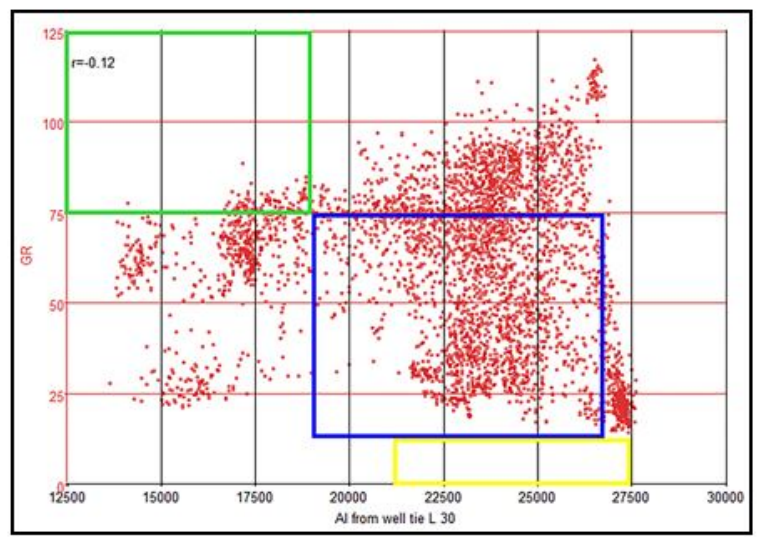

Gambar 4 Crossplot gamma ray dan AI pada sumur L30

Nilai gamma ray 0-20 API menunjukkan limestone dan nilai gamma ray 75-125 API menunjukkan batuan shale dan memiliki nilai impedansi akustik yang rendah yaitu 12500$20000(\mathrm{~m} / \mathrm{s})^{*}(\mathrm{~g} / \mathrm{cc})$. Hal ini mengindikasikan bahwa batuan shale mudah dimampatkan. Batuan sandstone ditunjukkan dengan nilai gamma ray sekitar 20-75 API serta memiliki nilai impedansi akustik yang tinggi yaitu 20000-27500 (m/s)*(g/cc). Hal tersebut menunjukkan bahwa sandstone sukar untuk dimampatkan. Analisis sensitivitas crossplot antara log gamma ray dan impedansi akustik pada sumur L30 menunjukkan dominasi batuan terbesar yaitu pada batuan sandstone.

\subsection{Analisis Atribut Dekomposisi Spektral}

Zona yang diduga sebagai prospek hidrokarbon adalah yang memiliki warna variance hitam dan memiliki ketidakmenerusan yang jelas dan ditandai dengan kotak hijau seperti yang ditunjukkan pada Gambar 5. Hasil yang ditunjukkan setelah dilakukaan penambahan atribut dekomposisi spektral dengan frekuensi $10 \mathrm{~Hz}$ lebih baik daripada tanpa atribut karena menampilkan kemenerusan yang lebih jelas.

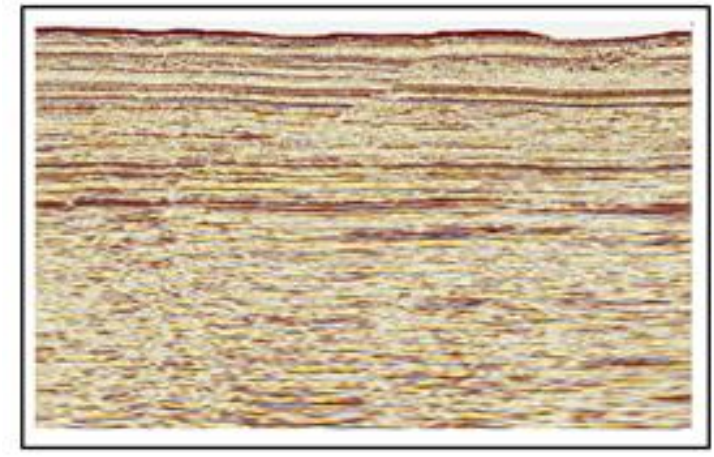

(a)

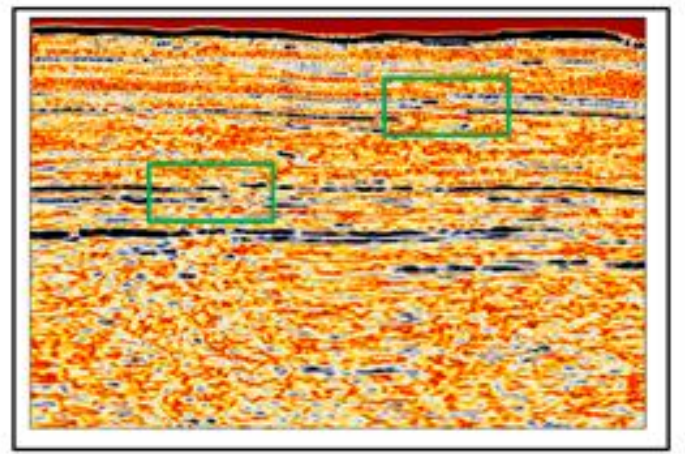

(b)

Gambar 5 Tampilan penampang seismik (a) tanpa atribut (b) penambahan atribut dekomposisi spektral $10 \mathrm{~Hz}$

\subsection{Analisis Inversi Deterministik}

Penampang vertikal impedansi akustik yang diperoleh dari hasil inversi deterministik ditunjukkan pada Gambar 6. Penampang model impedansi akustik dihasilkan dari dekonvolusi 
dari wavelet hasil ekstraksi wavelet dan nilai impedansi akustik dari proses WST. Penampang model impedansi akustik ini diinterpretasikan sebagai model gambaran permukaan bumi yang diwakili oleh zona-zona impedansi akustik yang berbeda berdasarkan skala warna. Hasil penampang impedansi akustik pada sumur L30 memiliki rentang nilai impedansi akustik antara $13556-27501(\mathrm{~m} / \mathrm{s})^{*}(\mathrm{~g} / \mathrm{cc})$ dan sumur B41 memiliki rentang nilai $16230-26143(\mathrm{~m} / \mathrm{s})^{*}(\mathrm{~g} / \mathrm{cc})$.

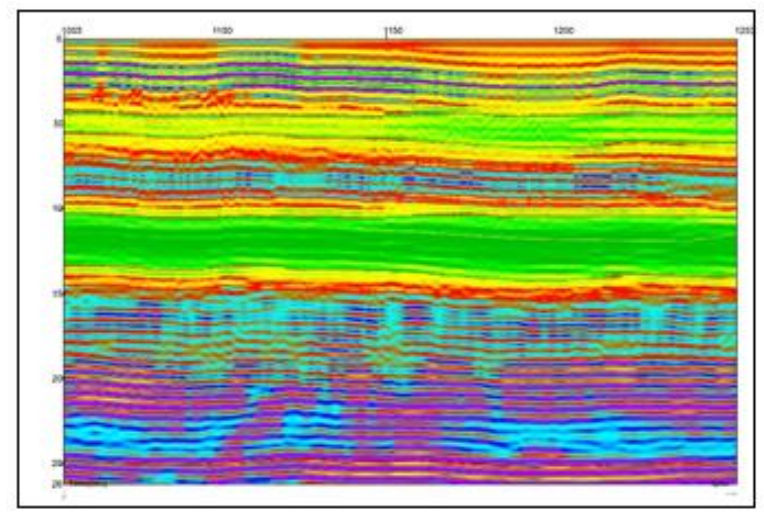

Gambar 6 Penampang impedansi akustik hasil inversi deterministik

Nilai impedansi akustik yang rendah diindikasikan sebagai batuan shale yang mudah dimampatkan dan dapat melewatkan gelombang seismik yang memiliki kecepatan tinggi. Nilai impedansi akustik yang tinggi diindikasikan sebagai reservoar hidrokarbon yaitu sandstone. Struktur sandstone yang padat mengakibatkan nilai impedansi akustik yang tinggi sehingga menghambat lewatnya gelombang seismik atau sukar dimampatkan. Hal tersebut mengakibatkan zona yang memiliki nilai impedansi akustik yang tinggi pada warna jingga sesuai dengan zone of interest dari spektral dekomposisi, sehingga dapat dilakukan slicing untuk melihat penampang secara horizontal.

\subsection{Slicing}

Gambar 7(a) menunjukkan hasil dari slicing porositas dan Gambar 7(b) menunjukkan slicing sebaran impedansi akustik (AI) pada lapisan (horizon) yang diindikasikan sebagai zone of interest. Sebaran dari porositas memiliki nilai yang cukup tinggi pada warna yang lebih gelap. Nilai porositas yang tinggi diindikasikan bahwa batuan memiliki pori-pori yang mampu menampung fluida. Hal ini menunjukkan zona tersebut memiliki kandungan minyak dan gas yang tinggi.

Berdasarkan warna penampang AI tersebut terlihat bahwa warna yang dominan ditunjukkan oleh zona berwarna jingga hingga ungu. Warna tersebut diindikasikan memiliki nilai impedansi akustik yang tinggi berkisar dari 20000-25461 (m/s)*(g/cc). Nilai impedansi terendah ditunjukkan pada warna hijau dengan nilai sebesar $14632(\mathrm{~m} / \mathrm{s})^{*}(\mathrm{~g} / \mathrm{cc})$. Hasil slicing penyebaran impedansi akustik ini menunjukkan bahwa lapisan tersebut didominasi oleh hidrokarbon dari reservoar sandstone.

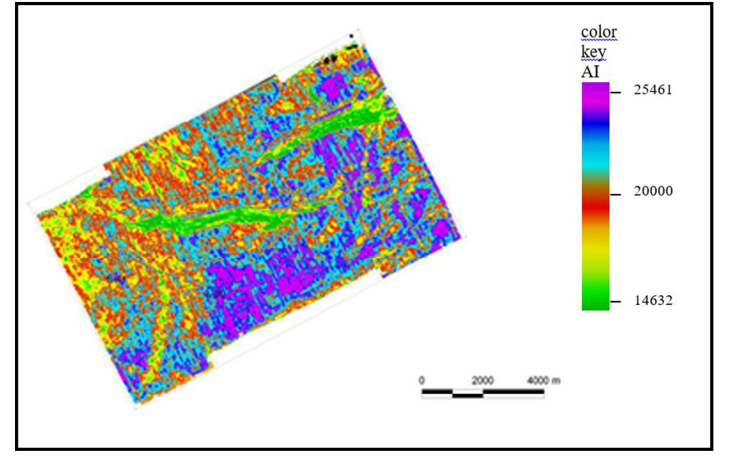

(a)

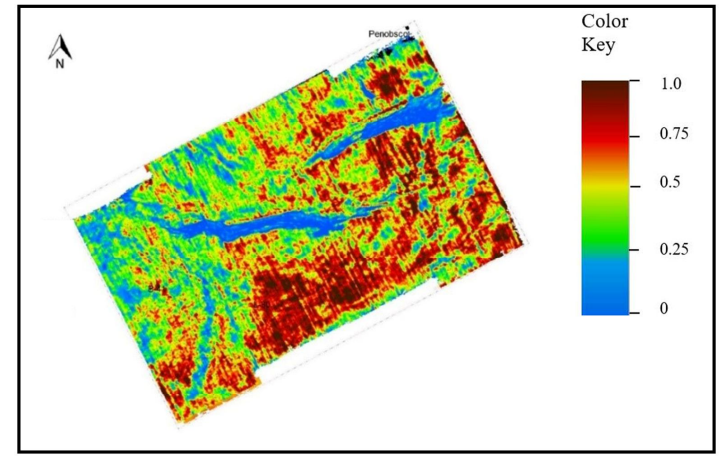

(b)

Gambar 7 Tampilan proses slicing (a) porositas (b) impedansi akustik 
Berdasarkan hasil slicing porositas dan impedansi akustik menunjukkan hasil bahwa pada daerah yang memiliki potensi hidrokarbon berada pada nilai porositas yang tinggi dan nilai impedansi akustik yang tinggi. Nilai impedansi akustik dipengaruhi oleh densitas dan kecepatan gelombang $\mathrm{P}$, jika densitas dari batuan semakin besar maka batuan tersebut sangat rapat. Pada batuan jika nilai porositas yang tinggi menunjukkan batuan memiliki pori-pori yang banyak didalamnya. Tapi pada batuan yang memiliki hidrokarbon akan terjadi anomali saat dilewatkan oleh gelombang P karena jika batuan tersebut mengandung fluida berupa hidrokarbon maka gelombang tersebut akan sulit untuk dimampatkan. Sehingga tidak semua batuan yang memiliki porositas yang tinggi memiliki kandungan hidrokarbon yang tinggi. Hal tersebut diakibatkan oleh kandungan dari batuan tersebut apakah mengandung hidrokarbon berupa minyak atau gas atau dapat ditunjukkan melalui nilai impedansi akustik yang tinggi.

\section{KESIMPULAN}

Berdasarkan karakterisasi reservoar yang telah dilakukan pada Lapangan Penobscot maka dapat disimpulkan bahwa hasil analisis crossplot menunjukkan bahwa log gamma ray dan log impedansi akustik sensitif dalam pemisahan lapisan shale, sandstone, dan limestone, Analisis atribut dekomposisi spektral dengan frekuensi $10 \mathrm{~Hz}$ dapat menunjukkan zone of interest dengan jelas sebagai indikasi adanya hidrokarbon dengan lebih mudah, Slicing yang dilakukan pada lapisan zone of interest di inline 1300 menunjukkan hasil yang jelas dari sebaran nilai impedansi akustik dengan rentang $13556-27501(\mathrm{~m} / \mathrm{s})^{*}(\mathrm{~g} / \mathrm{cc})$, dan daerah penelitian memiliki potensi hidrokarbon dengan reservoar sandstone pada zona impedansi akustik yang tinggi pada nilai $20000-25461(\mathrm{~m} / \mathrm{s})^{*}(\mathrm{~g} / \mathrm{cc})$.

\section{DAFTAR PUSTAKA}

Badley, M.E., Practical Seismic Interpretation International Human Human Resource Development Co, 1985.

Khasanah, H., Estimasi Penyebaran Porositas Reservoir Sandstone pada Lapangan Eksplorasi Hidrokarbon Penobscot Kanada, Skripsi, Jurusan Fisika, Universitas Jember, 2016.

Koesoemadinata, R.P., Geologi Minyak dan Gas Bumi Jilid 1, Institut Teknologi Bandung, Bandung, 1980.

Nofriyanti, S., dan Namigo, E., L., Karakterisasi Reservoar Mengunakan Inversi Deterministik pada Lapangan F3 Laut Utara Belanda, Jurnal Fisika Unand, Vol 5(2), (2016).

Sukmono, S., Seismik Inversi Untuk Karakterisasi Reservoar, Geophysical Engineering, Institut Teknologi Bandung, Bandung, 2000.

Tullailah, N., Lantu, A., Sabrianto., "Karakterisasi Reservoar Karbonat menggunakan Analisis Seismik Atribut dan Inversi Impedansi Akustik (AI) Pada Formasi Kais, Lapangan "NNT", Cekungan Salawati, Papua", Program Studi Geofisika FMIPA Universitas Hasanuddin, 2015.

Whitcombe, D.N. dan Fletcher, J.G., The AIGI Crossplot as an Aid to AVO Analysis and Calibration. Pada: SEG Int'1 Exposition and Annual Meeting, San Antonio, Texas 9-14 September, Texas, 2001

Cooke, D., dan Cant, J., 2010, Model Based Seismic Inversion Comparing Deterministic and Probabilistic Inversion, https://csegrecorder.com /articles/view/model-based-seismicinversion-comparing-deterministic-and-probabilistic, diakses Desember 2018.

International Energy Agency, 2017. Global Energy Demand Grew By 2.1\% In 2017, an Carbon Emissions Rose For The First Time Since 2014, https://www.iea.org/ newsroom/news/2018/march/global-energy-demand-grew-by-21-in-2017-and-carbonemissions-rose-for-the-firs.html, diakses Oktober 2018. 